\title{
Effect of Cell Seeding Density and Inflammatory Cytokines on Adipose Tissue-Derived Stem Cells: an in Vitro Study
}

\author{
Panithi Sukho ${ }^{1,2,3}$ (1) • Jolle Kirpensteijn ${ }^{1,4}$ - Jan Willem Hesselink ${ }^{1}$. \\ Gerjo J. V. M. van Osch ${ }^{2,5}$ • Femke Verseijden ${ }^{1,5}$ • Yvonne M. Bastiaansen-Jenniskens ${ }^{5}$
}

Published online: 24 January 2017

(C) The Author(s) 2017. This article is published with open access at Springerlink.com

\begin{abstract}
Adipose tissue-derived stem cells (ASCs) are known to be able to promote repair of injured tissue via paracrine factors. However, the effect of cell density and inflammatory cytokines on the paracrine ability of ASCs remains largely unknown. To investigate these effects, ASCs were cultured in 8000 cells $/ \mathrm{cm}^{2}, 20,000$ cells $/ \mathrm{cm}^{2}, 50,000$ cells/ $\mathrm{cm}^{2}$, and 400,000 cells/ $/ \mathrm{cm}^{2}$ with and without 10 or $20 \mathrm{ng} / \mathrm{ml}$ tumor necrosis factor alpha (TNF $\alpha$ ) and 25 or $50 \mathrm{ng} / \mathrm{ml}$ interferon gamma (IFN $\gamma)$. ASC-sheets formed at 400,000 cells/ $\mathrm{cm}^{2}$ after $48 \mathrm{~h}$ of culture. With increasing concentrations of $\mathrm{TNF} \alpha$ and IFN $\gamma$, ASC-sheets with $400,000 \mathrm{cells} / \mathrm{cm}^{2}$ had increased production of angiogenic factors Vascular Endothelial Growth Factor and Fibroblast Growth Factor and decreased expression of pro-inflammatory genes TNFA and Prostaglandin Synthase 2 (PTGS2) compared to lower density ASCs. Moreover, the conditioned medium of ASCsheets with 400,000 cells $/ \mathrm{cm}^{2}$ stimulated with the low concentration of TNF $\alpha$ and IFN $\gamma$ enhanced endothelial cell
\end{abstract}

Electronic supplementary material The online version of this article (doi:10.1007/s12015-017-9719-3) contains supplementary material, which is available to authorized users.

Yvonne M. Bastiaansen-Jenniskens

y.bastiaansen@erasmusmc.nl

1 Department of Clinical Sciences of Companion Animals, Faculty of Veterinary Medicine, Utrecht University, Utrecht, The Netherlands

2 Department of Otorhinolaryngology, Erasmus MC University Medical Center, Rotterdam, The Netherlands

3 Department of Clinical Sciences and Public Health, Faculty of Veterinary Science, Mahidol University, Nakhon Pathom, Thailand

4 Hills Pet Nutrition Inc, Topeka, Kansas, USA

5 Department of Orthopaedics, Erasmus MC University Medical Center, Wytemaweg 80, 3015, CN Rotterdam, The Netherlands proliferation and fibroblast migration. These results suggest that a high cell density enhances ASC paracrine function might beneficial for wound repair, especially in proinflammatory conditions.

Keywords Adipose tissue-derived stem cell · Cell sheet . Seeding density $\cdot$ Inflammatory cytokine and paracrine ability

\section{Introduction}

It is widely accepted that paracrine factors and cytokines from adipose tissue-derived stem cells (ASCs) can promote repair of injured tissue and/or improve the quality of tissues that are regenerated [38, 40, 41]. Traditionally, ASCs have been injected as cell suspension or have been combined with biomaterials before being delivered to injured tissue $[2,11,19$, $25,29]$. Recently, cell sheet engineering has been used to produce multicellular high density ASC-sheets that can be applied as a patch to injured tissue. Extracellular matrix, cell-cell and cell-matrix adhesions are preserved in engineered cell sheets thereby providing a niche and benefiting the attachment to tissue [39]. Several groups demonstrated that ASCsheets are able to promote repair in different types of tissues such as skin $[4,16,20,39]$ and myocardium $[13,14,23,27$, 37]. Formation of high-density ASC-sheets may influence the paracrine ability of ASCs [17] and subsequently affect their ability to promote tissue repair. Likewise, inflammatory cytokines present in injured tissues may impact ASCs function. Details about the effect of cell density and inflammatory cytokines on the paracrine ability of ASCs are largely unknown.

To elucidate these effects, we cultured ASCs in four different cell-seeding densities, with the highest density of 400,000 cells $/ \mathrm{cm}^{2}$ resulting in actual sheets. Cells were cultured with and without tumor necrosis factor alpha $(\mathrm{TNF} \alpha)$ and 
interferon gamma (IFN $\gamma)$ to simulate an inflammatory environment. We demonstrated that ASCs cultured in a cell sheet at a density of 400,000 cells $/ \mathrm{cm}^{2}$ have superior paracrine abilities when compared to ASCs cultured in lower cell densities in the presence of inflammatory factors. These findings offer opportunities to modify the beneficial effect of ASC-sheets for application in various tissues in the future.

\section{Materials and Methods}

\section{Isolation and Characterization of ASCs}

Human subcutaneous abdominal adipose tissue was obtained as waste material from female donors (age 46-52 years) with approval of the Medical Ethical Committee of the Erasmus Medical Center, Rotterdam (MEC-2014-092). ASCs were isolated as previously described [35]. Briefly, adipose tissue was digested with collagenase type I (Gibco, Life technologies, UK) for $1 \mathrm{~h}$ followed by centrifugation, washing to remove the oily layer including the adipocytes, and filtration through a $100 \mu \mathrm{m}$ filter. Isolated ASCs were cultured in expansion medium (Dulbecco's Modified Eagle Medium 1 g/l glucose (LGDMEM, Gibco) with $10 \%$ fetal bovine serum (FBS, Lonza, Verviers, Belgium), $50 \mu \mathrm{g} / \mathrm{ml}$ gentamicin (Gibco), $1.5 \mu \mathrm{g} / \mathrm{mL}$ fungizone ${ }^{\circledR}(\mathrm{Gibco})$ at $37^{\circ} \mathrm{C}$ in a humid atmosphere with $5 \%$ $\mathrm{CO}_{2}$. At $90 \%$ confluence, ASCs were subcultured with $0.25 \%$ trypsin EDTA (Gibco) and expanded starting at a density of $8000 \mathrm{cells} / \mathrm{cm}^{2}$ for use in the experimental set-up or stored in liquid nitrogen with 10\% DMSO (Sigma-Aldrich, St. Louis, MO, USA) in expansion medium.

Cell surface phenotype was determined by flow cytometric analysis using mouse anti-human monoclonal fluorescently labeled antibodies directed against CD45-PerCp, CD14FITC, CD34-APC, CD73-PE, HDL-DR-FITC (all BD Biosciences, San Jose, CA, USA), CD90-APC and CD105FITC (R\&D systems, Abingdon, UK) with dilutions according to manufacturer's instructions. Unstained ASCs were used as control. After antibody staining, cell suspensions were washed twice with FACS flow (BD, Biosciences), resuspended in $200 \mu \mathrm{l}$ FACS flow and directly analyzed on an eight colors FACSCANTO-II with FACSDIVA software (BD Biosciences) and FlowJo Software (Tree Star, Palo Alto, CA, USA).

To show multilineage differentiation capacity of the ASCs, adipogenic and osteogenic differentiation was performed in monolayer, and chondrogenic differentiation was performed in pellets as described previously [5]. To assess adipogenic differentiation, cells were stained with $0.5 \%$ Oil red O (Sigma) in isopropanol (Sigma). Osteogenic differentiation was assessed using Von Kossa staining with Thionin (Sigma). Pellets were fixed in $4 \%$ formalin overnight, paraffin embedded and sectioned $(6 \mu \mathrm{m})$ before staining for Glycosaminoglycans (GAGs) with $0.4 \%$ Thionin solution (Sigma), to assess chondrogenic differentiation.

\section{ASCs Seeding and Culture Conditions}

ASCs $\leq$ P4 were seeded in a 12-wells plate (Costar ${ }^{\circledR}$, Corning Inc., Corning, New York) in 4 different densities: $8000,20,000,50,000$ and 400,000 cells $/ \mathrm{cm}^{2}$ in expansion medium overnight. We used the seeding density of 8000 cells $/ \mathrm{cm}^{2}$ as a control in this experiment, since this seeding density is often used for expansion [7]. The seeding densities 20,000, 50,000 and 400,000 cells/ $\mathrm{cm}^{2}$ were selected based on previous studies examining cell sheets $[10,26,36]$. After overnight attachment, we refreshed the cells with LG-DMEM with $1 \% \mathrm{FBS}, 50 \mu \mathrm{g} /$ $\mathrm{ml}$ gentamicin and $1.5 \mu \mathrm{g} / \mathrm{ml}$ fungizone ${ }^{\circledR}$ (control condition). To induce inflammation, $10 \mathrm{ng} / \mathrm{ml} \mathrm{TNF} \alpha$ (PeproTech, Rocky Hill, New Jersey, USA) and $25 \mathrm{ng} /$ $\mathrm{ml}$ IFN $\gamma$ (PeproTech) -from now on referred to as low inflammatory condition-, or $20 \mathrm{ng} / \mathrm{ml} \mathrm{TNF} \alpha$ and $50 \mathrm{ng} /$ $\mathrm{ml}$ IFN $\gamma$-from now on referred to as high inflammatory condition-were added as used earlier [30] and culture was continued for $48 \mathrm{~h}$ (Fig. 1). After $48 \mathrm{~h}$ of culture, medium and cells were harvested for analyses.

\section{ASC-Sheets Histology}

ASC-sheets with a density of 400,000 cells $/ \mathrm{cm}^{2}$ were harvested $48 \mathrm{~h}$ after culture in a temperature responsive plate (CellSeed, Tokyo, Japan). Reducing the temperature to room temperature resulted in detachment of cells allowing processing for analysis. For this, ASC-sheets were fixed overnight in $4 \%$ buffered formaldehyde followed by embedding in paraffin. Sections were stained with hematoxylin and eosin (Sigma, St Louis, Missouri and Merck, Billerica, Massachusetts, USA)

\section{Gene Expression Analysis}

After $48 \mathrm{~h}$ of culture, ASCs were harvested with RLT lysis buffer (Qiagen, Hilden, Germany) plus $1 \% \beta$ mercaptoethanol (Sigma-Aldrich). Total RNA was extracted using the RNeasy micro kit (Qiagen) with on-column DNA digestion. Total RNA was quantified using a NanoDrop ${ }^{\mathrm{TM}} 1000$ spectrophotometer (Thermo Scientific, Wilmington, Delaware) according to manufacturer's instructions and 200 ng RNA was reverse transcribed into complementary DNA (cDNA) using Revert Aid First Strand cDNA Synthesis Kit (ThermoScientific). The mRNA levels of prostaglandin synthase (PTGS2, HS01573474_g1), indoleamine 2,3-dioxygenase (IDO1, HS00158027_m1) and FGF2 (HS00266645_m1) were analyzed with TaqMan ${ }^{\circledR}$ Gene 
Fig. 1 Experimental flowchart. (a) ASCs were isolated from 3 donors and seeded in 4 different densities and 3 different culture conditions for $48 \mathrm{~h}$. (b)

Conditioned medium collection. ASCs were cultured with TNF $\alpha$ and IFN $\gamma$ for $48 \mathrm{~h}$. Thereafter, medium was refreshed with culture medium containing no $\mathrm{TNF} \alpha$ and IFN $\gamma$. Following $24 \mathrm{~h}$ ASCs-conditioned medium samples were collected for analysis a

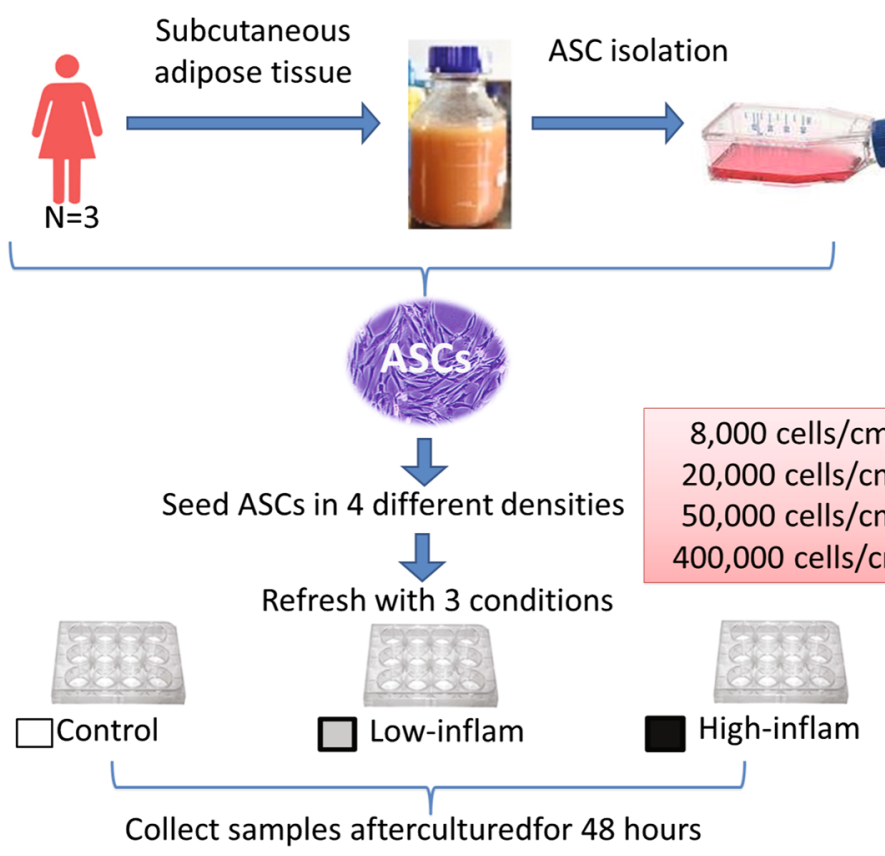

b

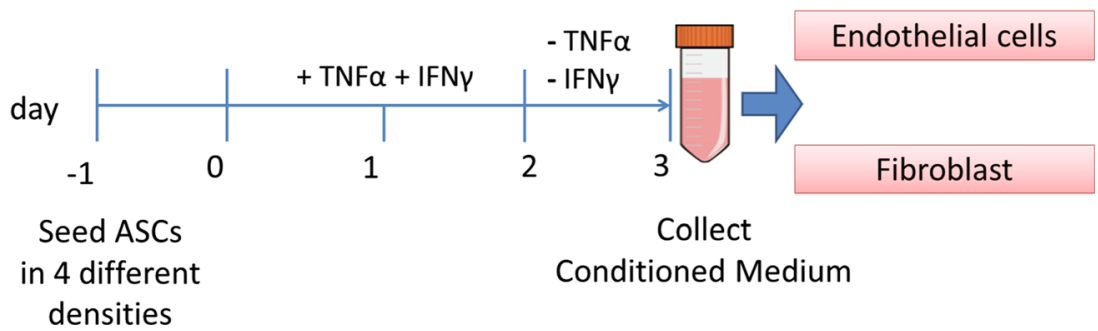

Expression Assays (Applied Biosystem, Foster City, California, USA) according to the manufacturer's instructions. Vascular endothelial growth factor A (VEGFA), tumor necrosis factor alpha (TNFA), transforming growth factor beta-1 $(T G F B)$ and glyceraldehyde-3-phosphate dehydrogenase $(G A P D H)$ were analyzed with the quantitative polymerase chain reaction (Q-PCR) MasterMix Plus for SYBR ${ }^{\circledR}$ Green I dTTP (Eurogentec, Seraing, Belgium) with the following gene-specific primer sets: VEGFA (Fw 5'-CTTG CCTTGCTGCTCTACC-3', Rv 5'- CACACAGGATGGCT TGAAG-3'), TNFA (Fw 5'-GCC-GCA-TCG-CCG-TCTCCT-AC-3', Rv 5'-AGC-GCT-GAG-TCG-GCT-ACC-CT3'), TGFB (Fw 5'-GTGACAGCAGGGATAACACACTG3', Rv 5'-CATGAatgGtGGCCAGGTC-3', Probe: ACATCAACGGGTTCACTACCGGC) and GAPDH (Fw 5'-GTCAACGGATTTGGTCGTATTGGG-3', Rv 5'-TGCC ATGGGTGgaAtCATATTGG-3', Probe: TGGCGCCC CAACCAGCC). As GAPDH was stable between experimental conditions, we used GAPDH for data normalization. Real-time Q-PCR was performed with Bio-Rad CFX96 Touch $^{\mathrm{TM}}$ Real-time PCR detection system and analyzed using CFX manager ${ }^{\mathrm{TM}}$ software (Bio-Rad Laboratories, Hemel Hempstead, UK). Relative expression was calculated according to the $2-\Delta \mathrm{CT}$ formula [31] using averages of duplicate samples.

\section{Analysis of Angiogenic Factors}

Culture media were analyzed for the concentration of ASC secreted angiogenic factors; VEGFA and FGF2 using commercially available sandwich human VEGFA and human FGF basic DuoSet $\AA$ ELISA kits (R\&D systems). According to the manufacturers' protocol, the optical density absorbance was determined at $450 \mathrm{~nm}$ with a reference wavelength of $540 \mathrm{~nm}$ in a VersaMax ${ }^{\mathrm{TM}}$ microplate reader. ELISA values are expressed as mean concentration of the total secreted factor per $\mathrm{ml} \pm \mathrm{SD}$.

\section{L-Kynurenine Assay}

Indoleamine-pyrrole 2,3-dioxygenase (IDO) is an enzyme that is able to inhibit T-cell proliferation via its metabolite Lkynurenine and thereby acts immune modulatory [30]. We determined the concentration of l-kynurenine as a measure of IDO activity in the culture medium as previously described by Leijs et al., 2012 [29] 


\section{ASC Viability}

Lactate dehydrogenase (LDH, Cytotoxicity Detection Kit, Roche, Mannheim, Germany) was measured to determine ASCs viability, according to the manufacturer's protocol. Briefly, medium of ASCs was collected after $48 \mathrm{~h}$ of culture and centrifuged at $1500 \mathrm{rpm}$ for $5 \mathrm{~min}$ to remove cells and debris. After that, $2 \%$ triton (Sigma-Aldrich) in LG-DMEM was added to the well and incubated for $2 \mathrm{~h}$ at $37^{\circ} \mathrm{C}$ to damage all cells and served as maximum control in the assay to calculate the percentage of viable cells. One hundred microliter of medium and $100 \mu \mathrm{l}$ lactate dehydrogenase reagent was mixed and incubated for $30 \mathrm{~min}$ in the dark at room temperature. The absorbance was measured with a VersaMax ${ }^{\mathrm{TM}}$ microplate reader (Molecular Devices, Sunnyvale, CA, USA) at $490 \mathrm{~nm}$ and a reference wavelength of $650 \mathrm{~nm}$. Percentage of cytotoxicity relative to the maximum control was calculated according to the manual.

\section{ASC Conditioned Medium}

To determine the effect of ASCs on fibroblast migration and endothelial cell proliferation, medium conditioned by ASCs in different densities in the presence of TNF $\alpha / \mathrm{IFN} \gamma$ was made. The low inflammatory condition $-10 \mathrm{ng} / \mathrm{ml} \mathrm{TNF} \alpha$ and $25 \mathrm{ng} /$ $\mathrm{ml}$ IFN $\gamma$ - is more close to physiologic concentrations of $\mathrm{TNF} \alpha$ and IFN $\gamma$ in injured tissue [33]. Additionally, gene expression profiles of ASCs were not different between the low and high inflammatory condition therefore medium was conditioned by ASCs cultured in different densities in the low inflammatory condition. Briefly, ASCs were seeded in densities of $8000,20,000,50,000$ and 400,000 cells $/ \mathrm{cm}^{2}$ and cultured in expansion medium overnight. After overnight culture, the expansion medium was replaced with LG-DMEM supplemented with $1 \%$ FBS, $50 \mu \mathrm{g} / \mathrm{ml}$ gentamicin, $1.5 \mu \mathrm{g} / \mathrm{mL}$ fungizone $\AA, 10 \mathrm{ng} / \mathrm{ml} \mathrm{TNF} \alpha$ and $25 \mathrm{ng} / \mathrm{ml} \mathrm{IFN} \gamma$ and cultured for another $48 \mathrm{~h}$. Following stimulation with TNF $\alpha$ and IFN $\gamma$, the ASCs were washed with PBS and refreshed with LGDMEM with $1 \%$ FBS, $50 \mu \mathrm{g} / \mathrm{ml}$ gentamicin, $1.5 \mu \mathrm{g} / \mathrm{ml}$ fungizone ${ }^{\circledR}$ but without $\mathrm{TNF} \alpha$ and IFN $\gamma$ and culture was continued. After $24 \mathrm{~h}$, conditioned medium (CM) was collected and centrifuged at $1500 \mathrm{~g}$ for $5 \mathrm{~min}$. The supernatant was stored in $-80^{\circ} \mathrm{C}$ until further analysis or used to culture endothelial cells and fibroblasts (Fig. 1b). Uncultured medium (LG-DMEM supplemented with $1 \% \mathrm{FBS}$ ) stored at $-80^{\circ} \mathrm{C}$ was used as control medium.

After media collection, each well was washed with PBS to remove non-attached cells, followed by addition of PBS to collect cells by scraping. Cells were digested overnight at $60^{\circ} \mathrm{C}$ with $250 \mu \mathrm{g} / \mathrm{ml}$ papain (Sigma-Aldrich). The DNA amount was measured with the Cyquant ${ }^{\circledR}$ cell proliferation assay kit (Invitrogen) according to the manufacturer's' protocol (Sigma-Aldrich).

\section{Endothelial Cell Proliferation Assay}

To test the effect of ASC-sheets on endothelial cell proliferation, human umbilical vein endothelial cells (HUVEC, Lonza) at P4 were seeded at a density of 5000 cells $/ \mathrm{cm}^{2}$ in a 96-wells plate and in a 24-wells plate and cultured overnight in endothelial growth medium (EGM-2 bullet kit, Lonza). The next day, cells were starved with $0.5 \%$ FBS in LG-DMEM for $3 \mathrm{~h}$. Then, HUVEC were refreshed with either control medium (LG-DMEM 1\% FBS) mixed with EGM medium (1:1) or medium conditioned by ASCs mixed with EGM medium (1:1). After $0,1,2,3$, and 4 days endothelial cell proliferation and viable cell numbers were determined with the Cyquant ${ }^{\circledR}$ cell proliferation assay kit (Invitrogen) and MTT assay, respectively. Combining the results from these assays will allow to (indirectly) have an indication about the proliferation. According to the manufacturers' protocol culture plates at $80^{\circ} \mathrm{C}$ were frozen after removal of medium. The proliferation on each day was analyzed using known numbers of HUVEC as a DNA standard. At room temperature, $200 \mu \mathrm{l}$ of CyQuant GR dye/lysis buffer was added to each well and incubated $5 \mathrm{~min}$ before reading the plate with the fluorescence microplate reader SpectraMax Gemini (Molecular Devices)

The MTT assay was based on the Mossman's protocol [24] to check for metabolically active cells.

\section{Fibroblast Migration Assay}

To investigate the migration of adult human dermal fibroblasts (HDFa, Gibco) in response to ASCs cultured in different densities, a scratch wound assay was performed with ASCsconditioned medium. A scratch wound assay seems most suitable in representing wound healing in vitro, based on the cell migration pattern and direction of cell migration $[15,18]$. HDFa $P \leq 6$ were plated at 10,000 cells $/ \mathrm{cm}^{2}$ in a 12 -wells plate and allowed to adhere overnight in HG-DMEM supplemented with $10 \% \mathrm{FBS}, 50 \mu \mathrm{g} / \mathrm{ml}$ gentamicin, and $1.5 \mu \mathrm{g} / \mathrm{ml}$ fungizone ${ }^{\circledR}$ to form a confluent monolayer. A linear wound was made in the cell layer of each well using a vertical scratch from a sterile $10 \mu \mathrm{l}$ pipette tip after marking the scratch location on the bottom of the well. Cell debris was removed, followed by adding $100 \%$ ASCs-conditioned medium or control medium. Wound closure was captured using a $10 \times$ objective with phase contrast microscopy every $2 \mathrm{~h}$ from 12 to $24 \mathrm{~h}$ after scratching. The photos were blinded and analyzed with TScratch software (CSElab, Zurich, Switzerland) [9]. The percentage of wound closure was quantified and normalized to the freshly made scratch, which was considered as $100 \%$ open wound area.

\section{Statistical Analysis}

Each experiment was repeated with 3 different ASCs donors and all experiments were performed in triplicate. Statistical 

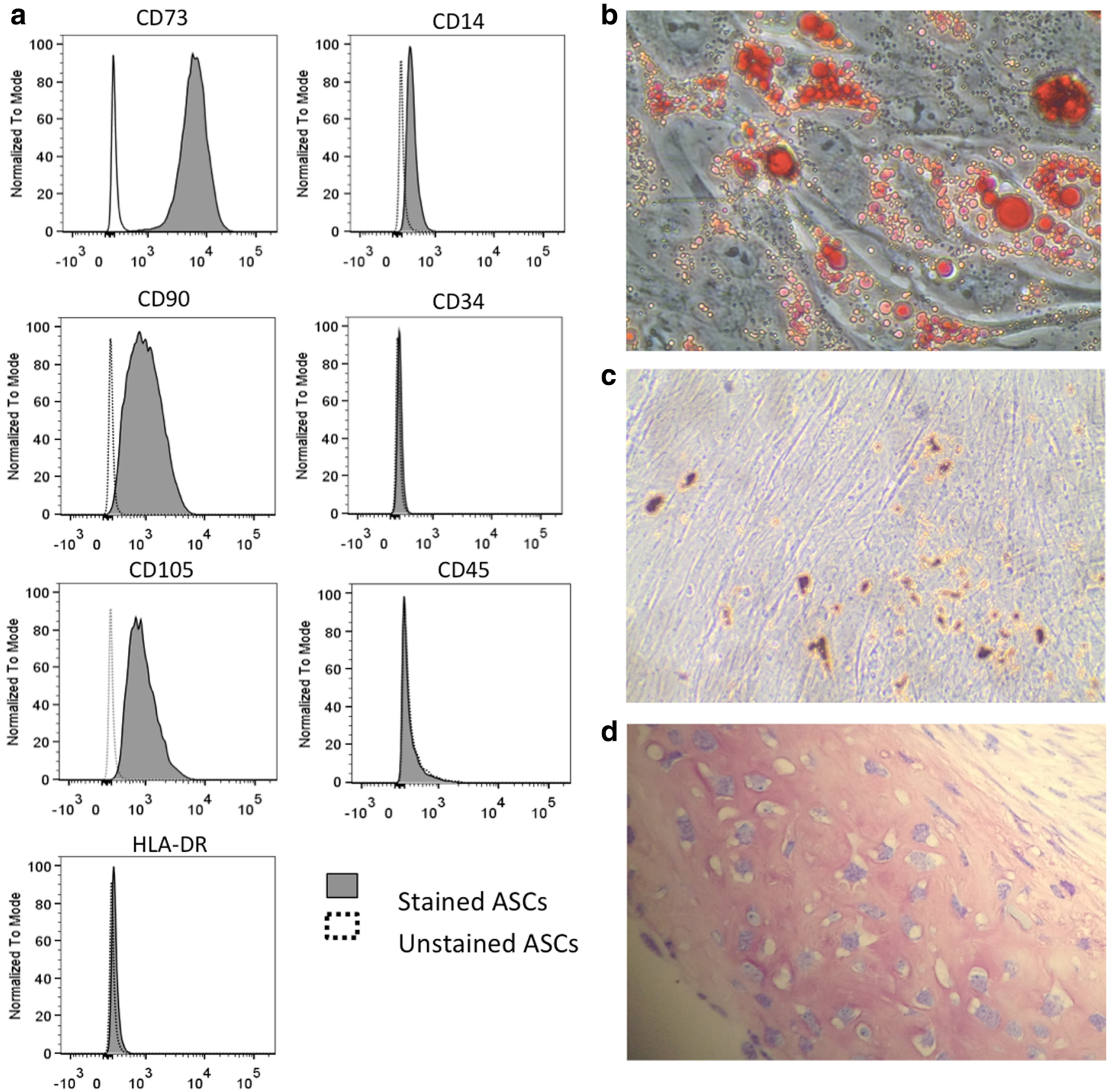

Fig. 2 ASCs characteristics. (a) Cultured ASCs were positive for CD73, CD90, CD105 and had minimal expression of CD14, CD34, CD45 and HLA-DR as determined with flow cytometric analysis. (b) Adipogenic differentiated ASCs were positive for accumulation of lipid-containing

analysis was done by one-way ANOVA for ASCs gene expression, protein analysis and viability followed by Bonferroni multiple comparisons. For the fibroblast migration assay and endothelial cell proliferation and viability, one-way MANOVA followed by Tukey HSD was used. Data were statistically analyzed with IBM SPSS statistical software 21 (SPSS, Inc., Chicago, IL, USA). A $p$-value $<0.05$ was considered to be statistically significant. Data were expressed as mean $\pm \mathrm{SD}$. droplets in the cytoplasm after staining with Oil Red O. (c) Osteogenic differentiated ASCs were positive for mineral deposition as stained with Von Kossa. (d) Chondrogenic differentiated ASCs pellets were positive for GAGs staining

\section{Results}

\section{ASC Characterization and Morphology}

To assess the phenotype of in vitro isolated and cultured ASCs, cell surface markers, morphology, and multilineage differentiation capacity were investigated. By FACS analysis (Fig. 2a), ASCs expressed mesenchymal stem cell markers such as CD73 (99.8\% $\pm 0.1 \%$ of the total cell population), 
CD90 $(90.3 \% \pm 9.1 \%)$ and CD105 $(87.4 \% \pm 17.0 \%)$, but only minimal hematopoietic markers such as CD14 (5.7\% $\pm 5.2 \%)$, CD45 $(1.6 \% \pm 0.6 \%)$ and CD34 $(4.4 \% \pm 3.9 \%)$ and human leukocyte antigen class II HDL-DR $(2.3 \% \pm 2.3 \%)$. Of notice, cell surface expression of CD73, CD90 and CD105 was a characteristic of the entire ASC population, thus operationally defining the homogeneity of the cells under study. As shown with the specific assays, ASCs also had differentiation capacities towards the adipogenic, osteogenic, and chondrogenic lineage (Fig. 2b). By phase-contrast microscopy, ASCs seeded at lower densities (8000-50,000 cells $/ \mathrm{cm}^{2}$ ) displayed a spindle-shaped fibroblast-like morphology (Fig. 3a-c). When seeded at 400,000 cells $/ \mathrm{cm}^{2}$, a multilayer, dense sheet of ASCs was seen (Fig. 3e, f).

\section{Effect of Cell Seeding Density and Inflammatory Cytokines on ASC Gene Expression}

In the control condition -without TNF $\alpha$ and IFN $\gamma$ - no significant differences were seen between the different cell seeding densities regarding gene expression of VEGFA, TGFB, TNFA, IDO and PTGS2.

The addition of TNF $\alpha$ and IFN $\gamma$ to the culture medium increased the expression of TNFA, IDO, PTGS2, VEGFA, and FGF2 for all cell-seeding densities whereas $T G F B$ decreased in response to these pro-inflammatory cytokines. Interestingly, the addition of TNF $\alpha / \mathrm{IFN} \gamma$ to 400,000 cells/ $\mathrm{cm}^{2}$ ASC-sheets affected the expression of TNFA, IDO and $P T G S 2$ the least. In contrast, the expression of VEGFA and $F G F 2$ after addition of TNF $\alpha / \mathrm{IFN} \gamma$ was affected the most in 400,000 cells $/ \mathrm{cm}^{2}$ ASC-sheets.

No significant changes in the expression of TNFA, IDO, $P T G S 2, V E G F A$ and $F G F 2$ were noticed with increasing concentrations of TNF $\alpha$ and IFN $\gamma$ in $8000,20,000$, and 50,000 cells $/ \mathrm{cm}^{2}$. Increasing concentrations of TNF $\alpha$ and IFN $\gamma$ increased PTGS2, VEGFA, FGF2 and decreased $T G F B$ expression in 400,000 cells/ $\mathrm{cm}^{2}$ ASC-sheets (Fig. 4a).

\section{Effect of Cell Seeding Density and Inflammatory Cytokines on ASCs Cytokine Secretion}

We assessed whether increases in cell density led to changes in ASCs secretion of L-kynurenine, a metabolite of the immunomodulatory enzyme IDO and the angiogenic factors VEGFA and FGF2. Secretion of the IDO metabolite L-kynurenine was not affected by cell seeding density. In contrast, VEGFA secretion increased with increasing seeding density in the control condition from $34.7 \pm 15 \mathrm{pg} / \mathrm{ml}$ at seeding density of 8000 cells $/ \mathrm{cm}^{2}$ to $2005 \pm 1394 \mathrm{pg} / \mathrm{ml}$ at seeding density of 400,000 cells $/ \mathrm{cm}^{2}$. Likewise, the secretion of FGF2 in ASC-sheets seeded at 400,000 cells $/ \mathrm{cm}^{2}$ was higher than by ASCs seeded at lower densities $\left[21.6 \pm 8 \mathrm{pg} / \mathrm{ml}\right.$ at 400,000 cells $/ \mathrm{cm}^{2}$ versus $11.7 \pm 5 \mathrm{pg} / \mathrm{ml}$ at 8000 cells $\left./ \mathrm{cm}^{2}\right]$.

Similar to observed changes in gene expression, the addition of TNF $\alpha$ and IFN $\gamma$ increased the secretion of VEGFA and FGF2. The highest levels of VEGFA, FGF2 and Lkynurenine levels were present in ASCs seeded at 400,000 cells $/ \mathrm{cm}^{2}$ with a seemingly dose dependent effect of TNF $\alpha$ and IFN $\gamma$ on VEGFA and FGF2 secretion (Fig. 4b).

\section{Analysis of ASC Viability}

As expected, an increase in cell seeding density resulted in decreased cell viability (as assessed by the LDH release) and a dose response was seen with increasing concentrations of TNF $\alpha$ and IFN $\gamma$ in ASCs with 80,000, 20,000 and 50,000
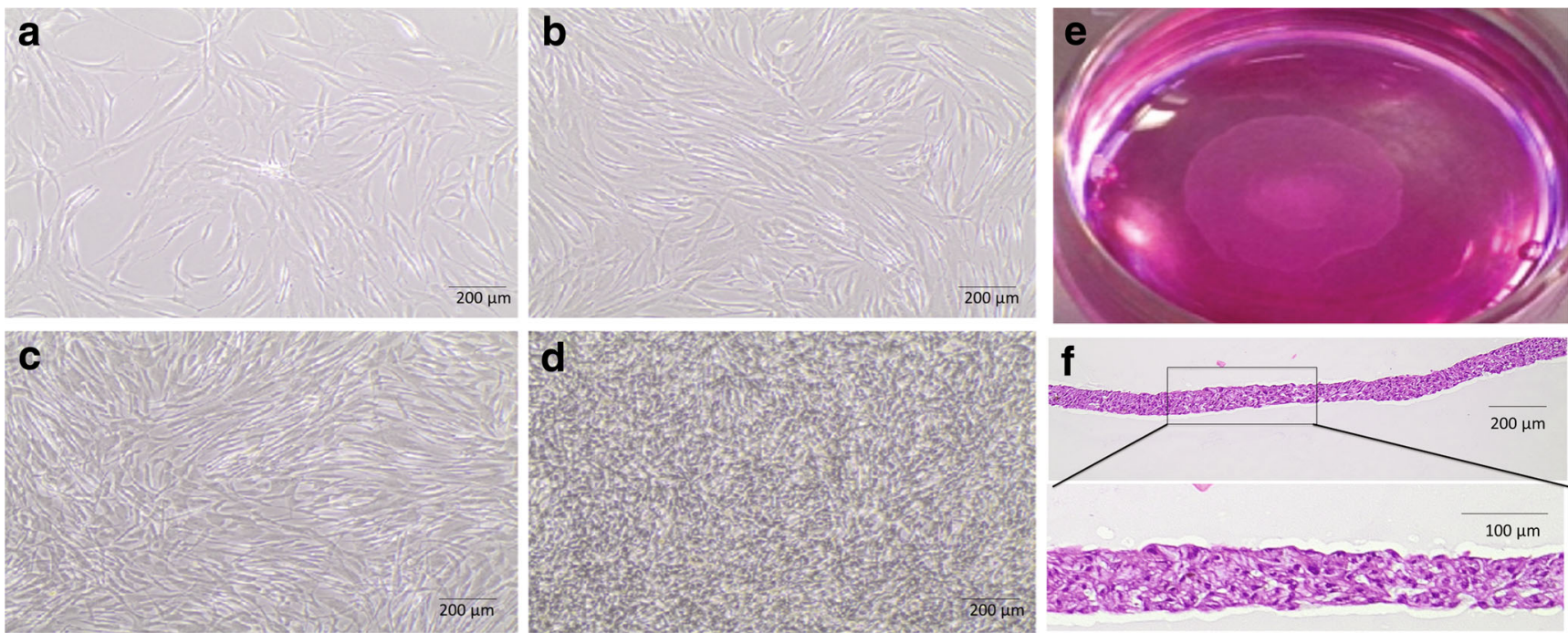

Fig. 3 ASCs morphology in different seeding densities. a-d) ASCs morphology $48 \mathrm{~h}$ after seeding at (a) $8000 \mathrm{cells} / \mathbf{c m}^{2}$, (b) 20,000 cells/ $\mathbf{c m}^{2}$, (c) 50,000 cells $/ \mathbf{c m}^{2}$ and (d) 400,000 cells/ $\mathbf{c m}^{2}$. (e) Image of a detached, floating ASC-sheet seeded at 400000 cells $/ \mathbf{c m}^{2}$. (f) Crosssection of a detached ASC-sheet stained with hematoxylin and eosin 

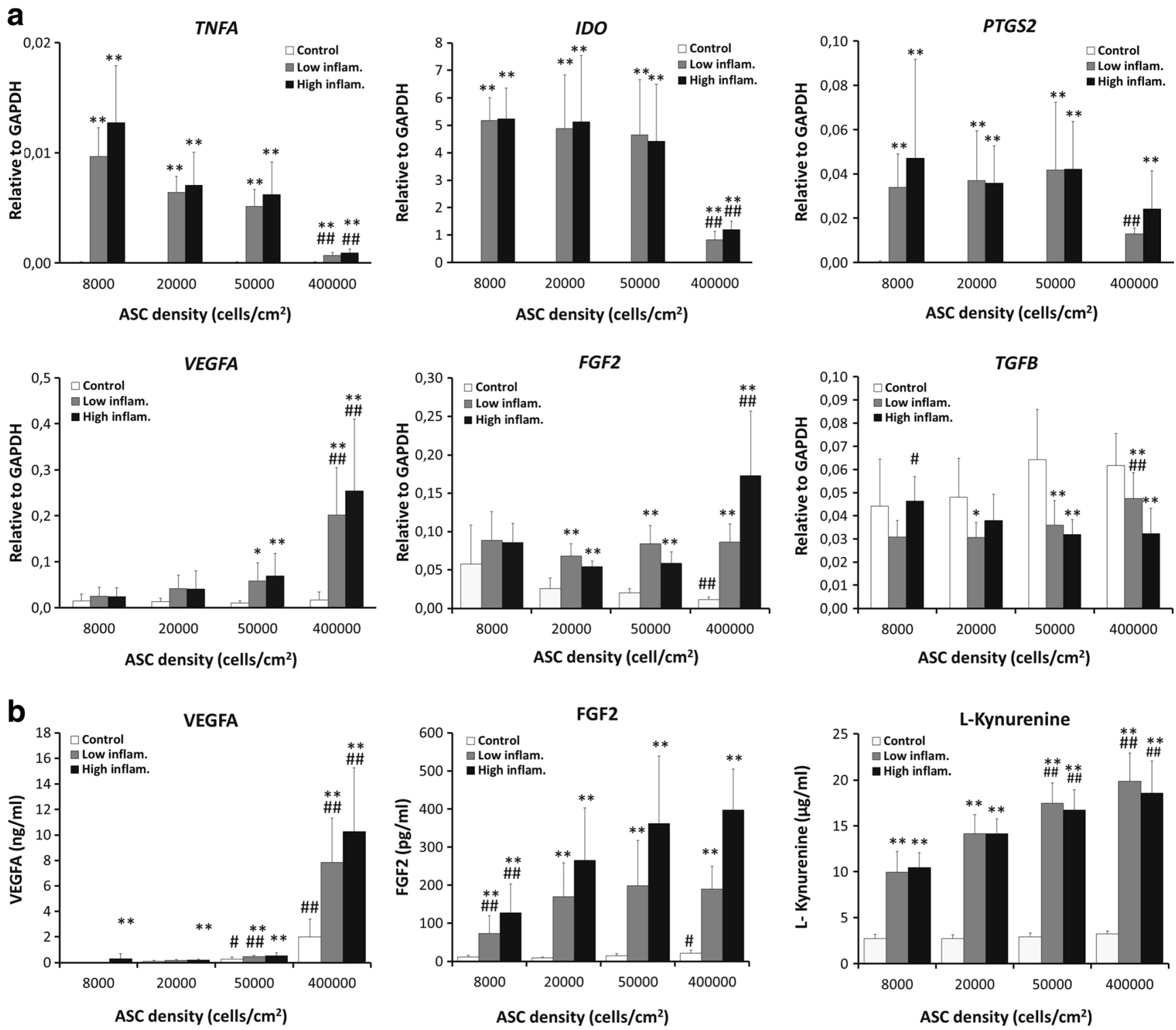

Fig. 4 Gene expression patterns and cytokine production of ASCs seeded at different cell densities and in the presence of inflammatory cytokines- $10 \mathrm{ng} / \mathrm{ml} \mathrm{TNF} \alpha+25 \mathrm{ng} / \mathrm{ml}$ IFN $\gamma$ (low inflammatory) and $20 \mathrm{ng} / \mathrm{ml} \mathrm{TNF} \alpha+50 \mathrm{ng} / \mathrm{ml}$ IFN $\gamma$ (high inflammatory)- (a) $T N F A, I D O$, $P T G S 2, V E G F A, F G F 2$ and TGFB expression relative to GAPDH and (b)

VEGFA, FGF2 and L-kynurenine production. Each bar represents mean \pm SD from 3 ASCs donors in triplicate $(* P<0.05$, $* * P<0.01$ when compared with control condition within same density, \# $P<0.05$, $\# \# P<0.01$ when compared within same culture condition)

cells $/ \mathrm{cm}^{2}$ except for the highest density of ASCs $(400,000$ cells $/ \mathrm{cm}^{2}$ ). However, seeding ASCs at 400,000 cells $/ \mathrm{cm}^{2}$ resulted in no further decline in cell viability when compared to lower cell seeding densities. Moreover, at 400,000 cells $/ \mathrm{cm}^{2}$ release of LDH remained low even though the concentration of inflammatory cytokines TNF $\alpha$ and IFN $\gamma$ increased (Fig. 5).

\section{Effect of ASC-Sheet Conditioned Medium on Fibroblast Migration and Endothelial Cell Proliferation}

With the scratch wound assay with HDFa and medium conditioned by ASCs more wound closure after $24 \mathrm{~h}$ was seen in
HDFa treated with conditioned medium from ASCs seeded at a density of 400,000 cells $/ \mathrm{cm}^{2}(32.3 \pm 15.9 \%$ open wound area) than in HDFa treated with control unconditioned medium (50 $\pm 13.8 \%$ open wound area) or in HDFa treated with conditioned medium from ASCs seeded at 8000 cells $/ \mathrm{cm}^{2}$ $\left(47.1 \pm 10.6 \%\right.$ open wound area) and 50,000 cells $/ \mathrm{cm}^{2}$ $(46.8 \pm 8.4 \%$ open wound area; $p<0.05$, Fig. $6 a)$.

The effect of ASC seeding density on HUVEC growth and survival was also assessed. On day 2, 3, and 4, endothelial cell numbers were significantly higher in conditioned medium from ASCs seeded at 400,000 cells $/ \mathrm{cm}^{2}$ than in conditioned medium from ASCs seeded at lower densities and control medium (Fig. 6b). HUVEC viability showed a similar trend; 


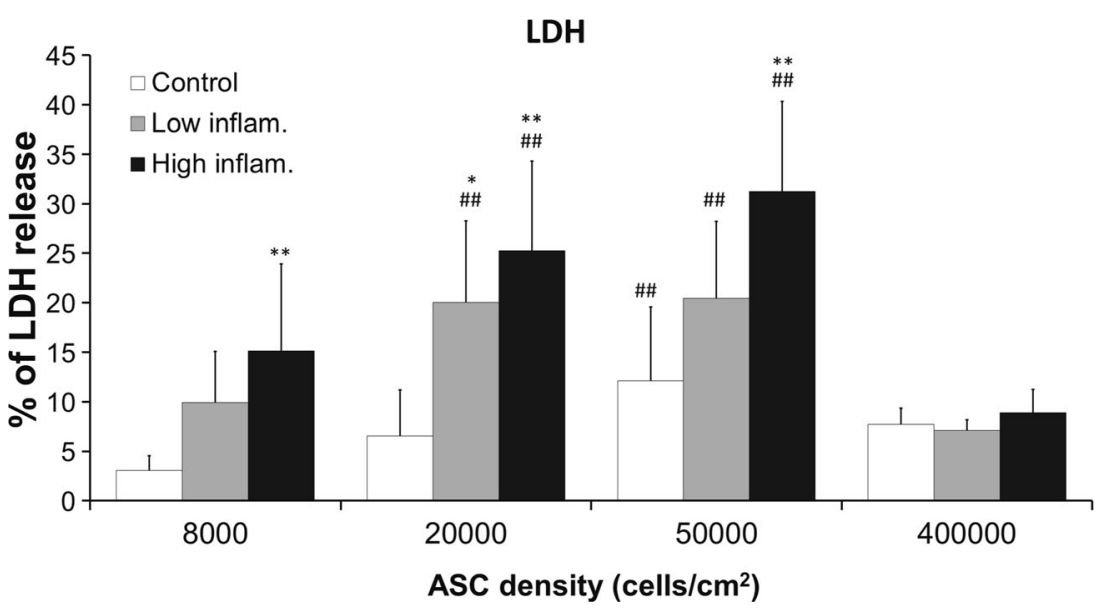

Fig. 5 ASCs survival assessed by LDH release. ASCs were cultured in the presence of inflammatory cytokines $-10 \mathrm{ng} / \mathrm{ml} \mathrm{TNF} \alpha+25 \mathrm{ng} / \mathrm{ml}$ IFN $\gamma$ (low inflammatory) and $20 \mathrm{ng} / \mathrm{ml} \mathrm{TNF} \alpha+50 \mathrm{ng} / \mathrm{ml} \mathrm{IFN} \gamma$ (high inflammatory)- and seeded at different densities. Each bar represents

the percentage of metabolically active endothelial cells was highest in conditioned medium from ASCs seeded at a 400,000 cells $/ \mathrm{cm}^{2}$ (Table 1).

The conditioned media that were used for these experiments had VEGFA and FGF2 levels in the same order of magnitude as when $\mathrm{TNF} \alpha$ and IFN $\gamma$ were still present, even though these stimuli were removed $24 \mathrm{~h}$ prior to harvesting the conditioned medium. In the case of VEGFA, the concentration increased with increasing ASC density. This effect was less clear for FGF2 (Fig. 6c).

\section{Discussion}

Here we show that organized multilayer ASC-sheets with 400,000 cells $/ \mathrm{cm}^{2}$ have superior paracrine characteristics when cultured in the presence of pro-inflammatory cytokines. The conditioned medium of these high-density ASC cultures are able to significantly enhance endothelial cell growth and fibroblast migration when compared to lower density ASC cultures.

In our study we used ASCs due to their therapeutic potential in regenerative medicine. For ASC isolation and characterization we used the accepted methods of isolation, plastic adherence, flow cytometric analysis, and multi-lineage differentiation. However, we cannot exclude the presence of small numbers of other cell types such as pre-adipocytes, endothelial progenitor cells, mast cells and others. Importantly, in this study we corroborate previous observations that ASCs at high seeding densities e.g. 400,000 cells $/ \mathrm{cm}^{2}$ form multicellular ASC-sheets that can be harvested as patches and expand these observations by showing an association of these high-density ASC-sheets with an improved cell viability, increased paracrine potential and upregulation of genes involved in immunosuppression when exposed to pro-inflammatory cytokines. average percentage $\mathrm{LDH}$ release $\pm \mathrm{SD}$ from 3 ASCs donors in triplicate. $(* P<0.05, * * P<0.01$ when compared to control condition in same density, \# $P<0.05$, \#\# $P<0.01$ when compared to control density ( 8000 cells $\left./ \mathrm{cm}^{2}\right)$ in same culture conditions)

In line with our expectations, increasing ASC seeding density decreased cell viability. However, increasing seeding density from 50,000 cells $/ \mathrm{cm}^{2}$ to 400,000 cells $/ \mathrm{cm}^{2}$ showed no further decline in cell viability. Additionally, TNFA gene expression decreased in response to increasing cell density under inflammatory conditions.

Previous studies have shown that pro-inflammatory cytokines as TNF $\alpha$ and IFN $\gamma$ can stimulate mesenchymal stem cells to produce more $\mathrm{TNF} \alpha, \mathrm{COX} 2$ (encoded by PTGS2), and IDO and less TGFB [6, 30]. IDO is an enzyme that is able to inhibit T-cell proliferation via its metabolite L-kynurenine and thereby acts immunomodulatory [32]. Similar to these previous reports, when we stimulated ASCs with TNF $\alpha$ and IFN $\gamma, T N F A, I D O$, and PTGS2 expression was higher than in unstimulated ASCs. Interestingly, the effect of proinflammatory stimulation by $\mathrm{TNF} \alpha$ and IFN $\gamma$ is less when ASCs are cultured in high density 400,000 cells $/ \mathrm{cm}^{2}$ ASCsheets. These high density ASC-sheets seem to be less influenced by inflammation. Moreover, increasing cell density and increasing concentrations of TNF $\alpha$ and IFN $\gamma$ resulted in the secretion of more VEGFA, FGF2, and L-kynurenine, emphasizing the potential benefit of these high density ASC-sheets for regenerative medicine purposes, even in the presence of inflammation.

We chose to show the secretion of VEGFA, FGF2 and L-kynurenine as total protein production since the actual amount of protein will exert its beneficial therapeutic effect in vivo, irrespective of how much is produced per individual cell. However, when we correct VEGFA secretion for cellular DNA, the secretion of VEGFA per cell is still higher in the highest density ASC-sheets (Supplementary data Fig. 1).

We confirm previous observations that ASCs seeded at higher density upregulated VEGFA gene expression [17]. Hsiao et al., 2013 [12] and others [3, 28] showed enhanced 
a

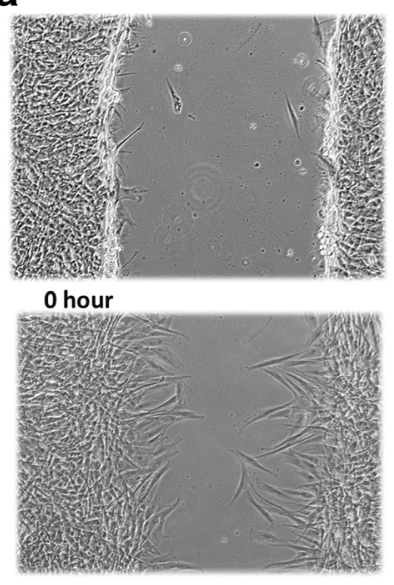

24 hours

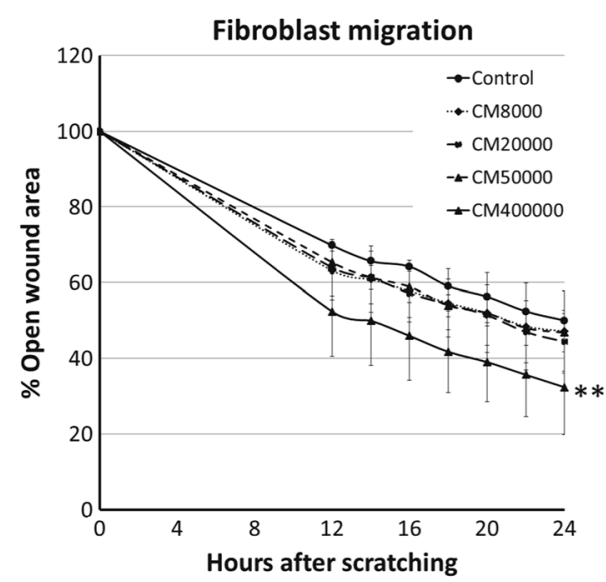

b

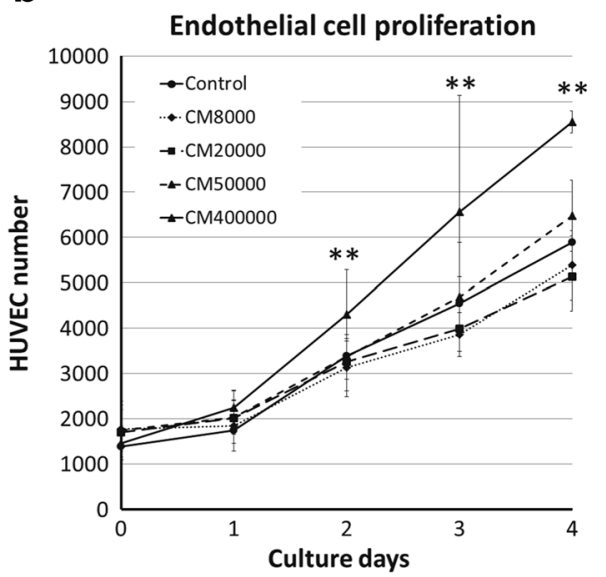

C

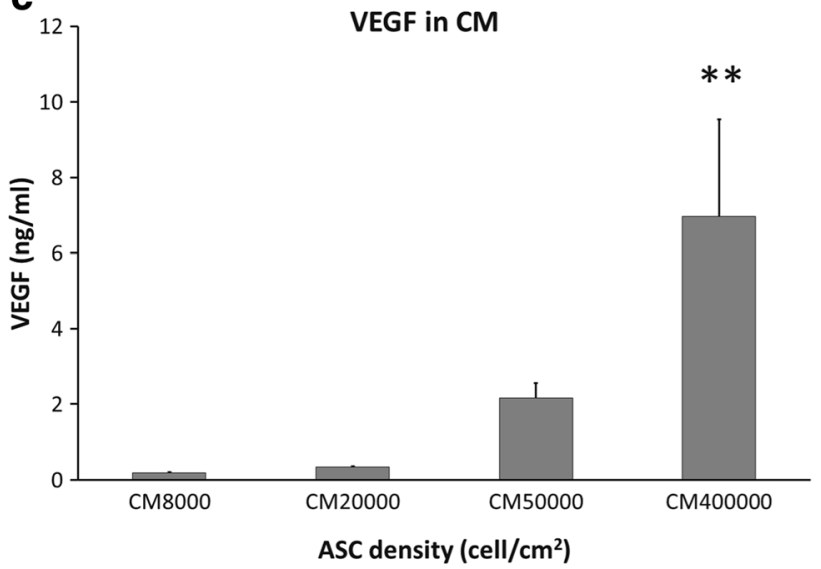

Fig. 6 Assessment of HDFa migration and HUVEC proliferation when cultured in conditioned medium from ASCs seeded at different densities (a) Left panel; representative images of the scratch wound assay right after making the wound (upper panel) and after $24 \mathrm{~h}$ (lower panel). Right panel; the effect of ASCs conditioned medium on $\mathrm{HDFa}$ migration. Each mark represents the average percentage of open wound area $\pm \mathrm{SD} ; n=3$ donors in triplicate wells. (b) The effect of conditioned

angiogenic paracrine activity of hypoxic ASCs in vitro. Following up on these observations the higher levels of VEGFA secretion in our multilayer $400,000 \mathrm{cells} / \mathrm{cm}^{2}$ ASCsheets might be due to some level of hypoxic stress.

The above-described results suggest that ASC-sheets with $400,000 \mathrm{cells} / \mathrm{cm}^{2}$ may have a higher ability to promote tissue repair than ASCs seeded at lower densities, especially under inflammatory conditions. To investigate this further, we obtained conditioned medium from ASCs seeded at different seeding densities and cultured in the presence of TNF $\alpha$ and IFN $\gamma$ and found that conditioned medium from 400,000 cells/ $\mathrm{cm}^{2}$ ASC-sheets significantly enhanced fibroblast migration and endothelial cell proliferation as two important processes in wound healing $[8,22,34]$ compared to control medium and conditioned medium from ASCs seeded at lower densities. Since VEGFA secretion was significantly increased in these ASC-sheets compared to lower density ASCs cultures, it is

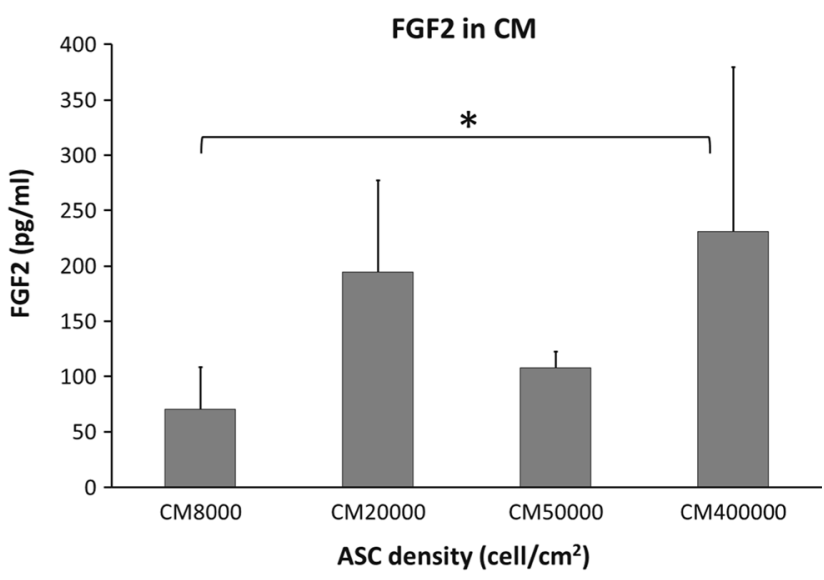

medium on HUVEC proliferation. Each mark represents average HUVEC number $\pm \mathrm{SD} ; n=3$ donors in triplicate wells $(* P<0.05$, $* * P<0.01$ when compared between densities). (c) Average concentration \pm SD of VEGFA and FGF2 in medium conditioned by ASCs from 3 ASCs donors $24 \mathrm{~h}$ after the removal of $10 \mathrm{ng} / \mathrm{ml} \mathrm{TNF} \alpha$ and $25 \mathrm{ng} / \mathrm{ml} \mathrm{IFN} \gamma$ and prior to adding to HUVEC and HDFa

possible that this growth factor contributed to the enhanced fibroblast migration and increased endothelial cell proliferation. However, besides VEGFA and FGF2 that we measured in our conditioned medium, the influence of other soluble factors in these processes is also very likely. Among many others, these factors could include TGF $\beta$, hepatocyte growth factor and multiple interleukins which are also secreted by ASCs [41], but also the bioactive lipid sphingosine-1 phosphate which is known as an pro-angiopoietic factor [1].

Taken together, our data demonstrate for the first time that ASCs seeded in high-density cell sheets are beneficial for fibroblast migration and endothelial cell proliferation in vitro. This is in agreement with studies directed at in vivo use of ASC-sheets. In these studies, the use of high density ASC-sheets was linked to enhanced tissue healing and angiogenesis $[10,13,14,21]$. In addition, our data indicate that stimulating ASC-sheets with pro-inflammatory stimuli 
Table 1 Percentage of metabolically active HUVEC after incubation with ASCs conditioned medium mixed with EGM (1:1)

\begin{tabular}{llll}
\hline ASC density (cells $\left./ \mathrm{cm}^{2}\right)$ & \multicolumn{2}{l}{ HUVEC culture (days) } \\
\cline { 2 - 4 } & 2 & 3 & 4 \\
\hline 8000 & $116 \pm 14 \%$ & $99 \pm 2 \%$ & $100 \pm 4 \%$ \\
20,000 & $121 \pm 22 \%$ & $90 \pm 1 \%$ & $92 \pm 17 \%$ \\
50,000 & $125 \pm 23 \%$ & $110 \pm 10 \%$ & $105 \pm 17 \%$ \\
400,000 & $151 \pm 29 \%^{* *}$ & $164 \pm 24 \%^{* * *}$ & $131 \pm 42 \%^{* *}$ \\
\hline
\end{tabular}

Percentage of metabolically active HUVEC in response to conditioned medium of ASCs seeded at different densities and collected after culture in a low inflammatory condition. Metabolically active HUVEC were measured using the MTT assay. Effects of conditioned medium on metabolic active HUVEC are shown as a percentage in the corresponding unconditioned media. Percentages are expressed as mean $\pm \mathrm{SD} ; n=3$ donors in triplicate wells. $* P<0.05 * * P<0.01 * * * P<0.005$ versus percentage of metabolically active HUVEC in unconditioned medium

in vitro may be beneficial regarding tissue vascularization. However, the possibility of improving tissue vascularization by culturing ASC-sheets with pro-inflammatory stimuli in vitro needs to be confirmed by further in vivo studies which was beyond the scope of the present project.

In summary, culturing ASCs in multilayer high-density sheets and stimulating them with inflammatory cytokines such as TNF $\alpha$ and IFN $\gamma$ changes their expression of immunomodulatory genes and improves their ability to promote cell proliferation and angiogenesis as demonstrated by a reduction in TNFA, IDO, and PTGS2 expression and augmentation of VEGFA secretion. Additionally, conditioned medium of these ASC-sheets enhanced fibroblast migration and endothelial cell proliferation in vitro, suggesting that using multilayer high density ASC-sheets cultured in the presence of TNF $\alpha$ and IFN $\gamma$ are potentially the better choice for the treatment of injured or ischemic tissues.

Acknowledgements The authors are grateful to Prof. Dr. S.E.R. Hovius, Dr. M.A.M. Mureau and all surgeons of the department of Plastic Surgery for the collection of subcutaneous adipose tissue, to Samantha de Witte (Department of Internal Medicine) for helping with FACS analysis, to Lizette Utomo (Department of Orthopaedics) for blinding the migration assay photos and to Assoc. Prof. Dr. Rudee Surarit (Department of Oral Biology, Faculty of Dentistry, Mahidol University, Thailand) for collaboration and laboratory training in Thailand.

\section{Compliance with Ethical Standards}

Author Disclosure Statement The authors declare that the research was conducted in the absence of any commercial or financial relationship that could be construed as a potential conflict of interest. P. Sukho is supported by a grant from The Netherlands Fellowship program (NFP$\mathrm{PhD}$ 12/435), during the conduct of the study. Y.M. BastiaansenJenniskensis supported by grants from Dutch Arthritis Association (LP11) and a Veni grant from NWO/STW. This study performed within the Postgraduated School Molecular Medicine, Erasmus University Medical center, The Netherlands.
Open Access This article is distributed under the terms of the Creative Commons Attribution 4.0 International License (http:// creativecommons.org/licenses/by/4.0/), which permits unrestricted use, distribution, and reproduction in any medium, provided you give appropriate credit to the original author(s) and the source, provide a link to the Creative Commons license, and indicate if changes were made.

\section{References}

1. Arya, D., Chang, S., Dimuzio, P., Carpenter, J., \& Tulenko, T. N. (2014). Sphingosine-1-phosphate promotes the differentiation of adipose-derived stem cells into endothelial nitric oxide synthase (eNOS) expressing endothelial-like cells. Journal of Biomedical Science, 21, 55.

2. Cai, L., Johnstone, B. H., Cook, T. G., et al. (2009). IFATS collection: human adipose tissue-derived stem cells induce angiogenesis and nerve sprouting following myocardial infarction, in conjunction with potent preservation of cardiac function. Stem Cells, 27, 230-237.

3. Cao, Y., Sun, Z., Liao, L., Meng, Y., Han, Q., \& Zhao, R. C. (2005). Human adipose tissue-derived stem cells differentiate into endothelial cells in vitro and improve postnatal neovascularization in vivo. Biochemical and Biophysical Research Communications, 332, 370-379.

4. Cerqueira, M. T., Pirraco, R. P., Santos, T. C., et al. (2013). Human adipose stem cells cell sheet constructs impact epidermal morphogenesis in full-thickness excisional wounds. Biomacromolecules, 14, 3997-4008.

5. De Mos, M., Koevoet, W. J., Jahr, H., et al. (2007). Intrinsic differentiation potential of adolescent human tendon tissue: an in-vitro cell differentiation study. BMC Musculoskeletal Disorders, 8, 16.

6. English, K., Barry, F. P., Field-Corbett, C. P., \& Mahon, B. P. (2007). IFN-gamma and TNF-alpha differentially regulate immunomodulation by murine mesenchymal stem cells. Immunology Letters, 110, 91-100.

7. Estes, B. T., Diekman, B. O., Gimble, J. M., \& Guilak, F. (2010). Isolation of adipose-derived stem cells and their induction to a chondrogenic phenotype. Nature Protocols, 5, 1294-1311.

8. Form, D. M., Pratt, B. M., \& Madri, J. A. (1986). Endothelial cell proliferation during angiogenesis. In vitro modulation by basement membrane components. Laboratory Investigation, 55, 521-530.

9. Geback, T., Schulz, M. M., Koumoutsakos, P., \& Detmar, M. (2009). TScratch: a novel and simple software tool for automated analysis of monolayer wound healing assays. BioTechniques, 46, 265-274.

10. Hamdi, H., Planat-Benard, V., Bel, A., et al. (2011). Epicardial adipose stem cell sheets results in greater post-infarction survival than intramyocardial injections. Cardiovascular Research, 91, 483-491.

11. Hong, S. J., Jia, S. X., Xie, P., et al. (2013). Topically delivered adipose derived stem cells show an activated-fibroblast phenotype and enhance granulation tissue formation in skin wounds. PloS One, 8, e55640.

12. Hsiao, S. T., Lokmic, Z., Peshavariya, H., et al. (2013). Hypoxic conditioning enhances the angiogenic paracrine activity of human adipose-derived stem cells. Stem Cells and Development, 22, 1614 1623.

13. Ishida, O., Hagino, I., Nagaya, N., et al. (2015). Adipose-derived stem cell sheet transplantation therapy in a porcine model of chronic heart failure. Translational Research, 165, 631-639.

14. Ishii, M., Shibata, R., Shimizu, Y., et al. (2014). Multilayered adipose-derived regenerative cell sheets created by a novel 
magnetite tissue engineering method for myocardial infarction. International Journal of Cardiology, 175, 545-553.

15. Justus, C. R., Leffler, N., Ruiz-Echevarria, M., \& Yang, L. V. (2014). In vitro cell migration and invasion assays. Journal of Visualized Experiments, 88, e51046.

16. Kato, Y., Iwata, T., Morikawa, S., Yamato, M., Okano, T., \& Uchigata, Y. (2015). Allogeneic transplantation of an adiposederived stem cell (ASC) sheet combined with artificial skin accelerates wound healing in a rat wound model of type 2 diabetes and obesity. Diabetes, 64, 2723-2734.

17. Kim, D. S., Lee, M. W., Yoo, K. H., et al. (2014). Gene expression profiles of human adipose tissue-derived mesenchymal stem cells are modified by cell culture density. PloS One, 9, e83363.

18. Kramer, N., Walzl, A., Unger, C., et al. (2013). In vitro cell migration and invasion assays. Mutation Research, 752, 10-24.

19. Lim, J. Y., Ra, J. C., Shin, I. S., et al. (2013). Systemic transplantation of human adipose tissue-derived mesenchymal stem cells for the regeneration of irradiation-induced salivary gland damage. $P l o S$ One, 8, e71167.

20. Lin, Y. C., Grahovac, T., Oh, S. J., Ieraci, M., Rubin, J. P., \& Marra, K. G. (2013). Evaluation of a multi-layer adipose-derived stem cell sheet in a full-thickness wound healing model. Acta Biomaterialia, 9, 5243-5250.

21. Makarevich, P. I., Boldyreva, M. A., Gluhanyuk, E. V., et al. (2015). Enhanced angiogenesis in ischemic skeletal muscle after transplantation of cell sheets from baculovirus-transduced adipose-derived stromal cells expressing VEGF165. Stem Cell Rerearch and Therapy, 6, 204.

22. Mcdougall, S., Dallon, J., Sherratt, J., \& Maini, P. (2006). Fibroblast migration and collagen deposition during dermal wound healing: mathematical modelling and clinical implications. Philosophical transactions. Series A, Mathematical, physical, and engineering sciences, 364, 1385-1405.

23. Miyahara, Y., Nagaya, N., Kataoka, M., et al. (2006). Monolayered mesenchymal stem cells repair scarred myocardium after myocardial infarction. Nature Medicine, 12, 459-465.

24. Mosmann, T. (1983). Rapid colorimetric assay for cellular growth and survival: application to proliferation and cytotoxicity assays. Journal of Immunological Methods, 65, 55-63.

25. Naaijkens, B. A., Van Dijk, A., Kamp, O., Krijnen, P. A., Niessen, H. W., \& Juffermans, L. J. (2014). Therapeutic application of adipose derived stem cells in acute myocardial infarction: lessons from animal models. Stem Cell Reviews and Reports, 10, 389-398.

26. Nash, M. E., Fan, X., Carroll, W. M., et al. (2013). Thermoresponsive substrates used for the expansion of human mesenchymal stem cells and the preservation of immunophenotype. Stem Cell Reviews and Reports, 9, $148-157$.

27. Otsuki, Y., Nakamura, Y., Harada, S., et al. (2015). Adipose stem cell sheets improved cardiac function in the rat myocardial infarction, but did not alter cardiac contractile responses to (beta)-adrenergic stimulation. Biomedical Research, 36, 11-19.
28. Park, B. S., Kim, W. S., Choi, J. S., et al. (2010). Hair growth stimulated by conditioned medium of adipose-derived stem cells is enhanced by hypoxia: evidence of increased growth factor secretion. Biomedical Research, 31, 27-34.

29. Rodriguez, J., Boucher, F., Lequeux, C., et al. (2015). Intradermal injection of human adipose-derived stem cells accelerates skin wound healing in nude mice. Stem Cell Research \& Therapy, 6 , 241.

30. Roemeling-Van Rhijn, M., Mensah, F. K., Korevaar, S. S., et al. (2013). Effects of hypoxia on the immunomodulatory properties of adipose tissue-derived mesenchymal stem cells. Frontiers in Immunology, 4, 203.

31. Takaku, Y., Murai, K., Ukai, T., et al. (2014). In vivo cell tracking by bioluminescence imaging after transplantation of bioengineered cell sheets to the knee joint. Biomaterials, 35, 2199-2206.

32. Terness, P., Bauer, T. M., Rose, L., et al. (2002). Inhibition of allogeneic $\mathrm{T}$ cell proliferation by indoleamine 2,3-dioxygenase-expressing dendritic cells: mediation of suppression by tryptophan metabolites. The Journal of Experimental Medicine, 196, 447-457.

33. Turner, D. A., Paszek, P., Woodcock, D. J., et al. (2010). Physiological levels of TNFalpha stimulation induce stochastic dynamics of NF-kappaB responses in single living cells. Journal of Cell Science, 123, 2834-2843.

34. Velnar, T., Bailey, T., \& Smrkolj, V. (2009). The wound healing process: an overview of the cellular and molecular mechanisms. The Journal of International Medical Research, 37, 1528-1542.

35. Verseijden, F., Jahr, H., Posthumus-Van Sluijs, S. J., et al. (2009). Angiogenic capacity of human adipose-derived stromal cells during adipogenic differentiation: an in vitro study. Tissue Engineering. Part A, 15, 445-452.

36. Wang, Z., Li, Z., Dai, T., Zong, C., Liu, Y., \& Liu, B. (2016). Addition of adipose-derived stem cells to mesenchymal stem cell sheets improves bone formation at an ectopic site. International Journal of Molecular Sciences, 17, 70.

37. Yeh, T. S., Dean Fang, Y. H., Lu, C. H., et al. (2014). Baculovirustransduced, VEGF-expressing adipose-derived stem cell sheet for the treatment of myocardium infarction. Biomaterials, 35, 174-184.

38. Yoshida, S., Yoshimoto, H., Hirano, A., \& Akita, S. (2016). Wound healing and angiogenesis through combined use of a vascularized tissue flap and adipose-derived stem cells in a rat Hindlimb ischemia model. Plastic and Reconstructive Surgery, 137, 1486-1497.

39. Yu, J., Tu, Y. K., Tang, Y. B., \& Cheng, N. C. (2014). Stemness and transdifferentiation of adipose-derived stem cells using L-ascorbic acid 2-phosphate-induced cell sheet formation. Biomaterials, 35, 3516-3526.

40. Zografou, A., Papadopoulos, O., Tsigris, C., et al. (2013). Autologous transplantation of adipose-derived stem cells enhances skin graft survival and wound healing in diabetic rats. Annals of Plastic Surgery, 71, 225-232.

41. Zuk, P. (2013). The ASC: Critical participants in paracrinemediated tissue health and function. In P. J. A. Andrades (Ed.), Regenerative medicine and tissue engineering. InTech: Rijeka. 